\title{
Research and Practice on the International Talent training Mode of Hotel Management
}

\author{
Qun Shang \\ Jiangsu Vocational Institute of Commerce, Nanjing, Jiangsu, China, 211168
}

Keywords: Hotel Management; International Talent; Training Model; Training Objectives

\begin{abstract}
With the deepening of the phenomenon of economic globalization, China and other countries in the political, cultural and other aspects of the exchange and integration is also greatly increased, various industries have increased the demand for international talent, which in the hotel industry's performance is particularly evident. This paper is mainly to the international hotel talent overview, the hotel management of international talent training objectives, hotel management international talent training model practice three aspects of a detailed analysis and research.
\end{abstract}

\section{Introduction}

From the beginning of the twenty-first century, Chinese hotel industry gradually to the direction of international development, which raised the front line of international service personnel requirements, but the hotel management international professional training, due to many aspects, There is a low level of teachers, teaching system and international out of touch, the concept of backward, unknown objectives and other issues, leading to the hotel management of national talent is always in a state of extreme shortage. In this context, the colleges and universities need to actively strengthen the training of hotel management international talent, build a scientific and rational training model, cultivate a large number of high-quality, national hotel management personnel to promote the development of Chinese hotel industry to provide talent support.

\section{The Overview of International Hotel Talent}

International hotel talent refers to the high-quality compound talents, these people in the process of hotel management need to stand in the international business perspective to think about the problem, look at the problem, not only need to be familiar with all the rules of international economic operation, the process of dealing with related events also need to follow the relevant laws and regulations, through the international business expertise to apply the flexibility to consider the issue. At the same time international hotel talent also need to have the basic foreign language communication skills and cultural skills, and understand the issues related to the hotel business countries [1]. But also need to stand in the regional, global perspective to in-depth analysis and research of international talent, smooth international awareness. In the definition of international talent, the most critical is the need to form a world-class knowledge structure, ideas need to stand at the forefront of the times, to the international level of competence, the opportunity to have a certain degree of sensitivity, and then grasp the development opportunities in time, but also need to work according to their own characteristics of the field initiative, and actively achieve innovation. In the context of the information age, international talent in dealing with the problem, the process of analysis of the problem requires the full application of information technology, strengthen their design capabilities. From the perspective of regionalization, hotel management personnel also need to establish a sense of national responsibility, although the international talent has a cross-regional, cross-regional characteristics, but its foundation and premise are based on the national culture, so in all foreign work, hotel management International workers need to stand on the basis of the characteristics of the nation, in the specific work to implement, which can also to a certain extent, improve the management of the overall quality and management capabilities. As a type of service 
industry, the people who come into contact with the hotel management have certain diversity, so the hotel managers need to master the language of the two countries except the mother tongue, and the language type the more good, which is to promote cultural exchanges is of great significance and role [2]. And in international exchanges, the hotel management staff also need to master a variety of skills, so the hotel management staff not only needs to master the relevant skills of knowledge, but also the accumulation of hotel management experience. International hotel management staff should have the ability to independently investigate, analyze and judge the market, and collect all kinds of technical resources and make use of it.

The hotel industry in different times facing the challenges and opportunities are not the same, so the hotel management staff need to quickly adapt to changes in the environment, according to local cultural characteristics to targeted to accept foreign culture, the international community is still in the midst of the international economy to build the local economic environment. In order to better integrate into the local culture in the process of globalization, international hotel talent can actively improve and optimize the local culture, the effective integration of globalization, the characteristics of the times and local characteristics. Global talent in the process of improving the ability to work, need to fully based on geographical characteristics and cultural environment characteristics, but in the globalization of the constant impact of globalization, talent cannot just passively accepted, but need to take the initiative to assume the local characteristics. Compound talents need to have the ability to synthesize different cultures, through the comprehensive analysis of the regional economic and cultural development characteristics summed up, and gradually innovative, perfect, in the trend of globalization to actively spread the local culture [3].

\section{The International Talent Training Objectives of Hotel Management}

The hotel is a high-level talented person in the hotel management and service. It needs to be engaged in foreign affairs. At the same time, it should bear the responsibility of carrying forward and inherit the local culture, and regard the local characteristics as the core content in the spread of foreign culture. In the training of hotel management international talent, we need to establish the following aspects of training objectives.

First of all need to guide the establishment of patriotic feelings, in the regional culture and local culture on the basis of the establishment of emotions, grasp the cultural characteristics of other cultures, the essence of other cultures in-depth analysis. At present, the world has gradually entered the era of knowledge economy, in the local, national economic development of the culture gradually occupy an important role in some areas and countries will set up an independent cultural brand, strengthen publicity and dissemination of local culture, which enhance their own cultural immunity Also has an important role [4]. Second, we need to improve their communication skills, cultivate hotel management international talent is based on national competitiveness, and also need to further strengthen its international cooperation awareness. Hotel management international talent need to strengthen the hotel management customs, history and culture and other related knowledge of learning, but also need to understand and master some of the international practice of the hotel industry. In the hotel management talent to emphasize the internationalization of its basic business skills is cross-cultural communication skills, so skilled use of English is its basic skills, but also need to understand the business-related countries, language, culture, and have a certain cultural and innovative ability. It can be seen that the cultivation of hotel management international talent is to improve the hotel management talent of the cultural integration, adaptability and immunity [5].

Cultural integration refers to the hotel management of international talent in the face of the surrounding environment changes in the process and you can use the global regional vision to conduct an objective review. Hotel management International talent only with cultural integration, can better adapt to the impact of global culture, adhere to the spread of local culture continue to carry forward the local culture. Cultural immunity refers to the process of international management of talent in the process of being influenced by the culture of other countries, the need to adhere to the local culture of communication and integration, to strengthen and carry forward their own regional culture and local culture, to minimize the foreign culture on the adverse effects of their 
own culture [6]. Cultural adaptability is based on the cultural immunity, refers to the hotel management of international talent in the face of other cultures, should be inclusive, accepted attitude to face, which is to achieve the basis of cultural innovation protection.

For these three capabilities, each other is interrelated and independent of each other, which is the basic ability of cultural immunity, the need to gradually adapt to the cultural adaptability, and ultimately to achieve cultural integration. When the hotel management of international talent has a cultural integration, adaptability and immunity, can truly achieve the global development of regional culture, and thus in the talent training process, not only need to fully show the characteristics of the hotel international talent, while But also need to improve its overall quality [7].

\section{The Hotel Management International Talent Training Mode Practice}

Select the Teaching Content and Set the Curriculum System According to the International Hotel Standards. If you want to train a large number of hotel management international talent, in the construction of the relevant teaching curriculum system when the need to international hotel as its basis. At the same time also need to be based on national education, the development of high-level hotel management personnel goals, which need to be based on teaching practice to achieve. In the set of teaching system and the choice of teaching content, the need to cultivate talent application capacity as a basic goal, and in the actual training process, should focus on the hotel management personnel comprehensive ability to improve.

The Construction of Modular Teaching System. In the training of hotel management international talent, the need to strengthen the modular curriculum teaching system construction, teaching objectives to students professional ability to cultivate the main. Which in the development of international personnel training objectives, but also should take full account of the international hotel employment needs. Modular construction is for each stage of training objectives, so different courses need to build a certain relationship between each other, and develop a professional curriculum plan. In the international management of hotel management personnel training mode, the need to international hotel employment as a guide, and the effective integration of professional ability, quality training and theoretical knowledge to improve, and the student's professional growth rules should also be strictly followed [8].

The Application of Bilingual Teaching Mode. According to the characteristics of international management of hotel management, bilingual teaching mode can be fully applied in teaching, which plays an important role in improving students' international communication ability. But also the need for effective convergence of hotel management courses and foreign language courses teaching, which students' vocational skills and related to the improvement of the overall quality of the important role, but also help to develop students' foreign language expression. In the specific operation of bilingual teaching mode, in order to ensure the quality of teaching, we need to implement the phased and hierarchical teaching according to the language foundation of the students, and gradually implement the bilingual teaching from the basic course, and finally realize the bilingual teaching mode in all courses.

Actively Set Up High-Quality International Teaching Team. In order to cultivate the international management of the hotel talent, the international teaching team is its important basic guarantee, which can also be a better adaptation to the development of tourism globalization, teaching team quality needs and international hotel management requirements in line. In the hotel management teaching, need to further deepen the teaching reform, which has an important role in improving the quality of teaching. In the actual teaching, you can take a variety of teaching models, such as inviting experts in the industry to carry out special lectures, to strengthen the practice of teaching and teaching integrated teaching mode of application, to guide students more intuitive, the image of their future professional image if conditions permit, you can also directly invite foreign teachers to carry out professional knowledge teaching, teaching ideas and teaching methods and international convergence [9]. 
Strengthen the Application of School-Enterprise Cooperation Model. Through the application of school-enterprise cooperation model, students can be able to improve their overall practice in the overall quality and ability, which the international management of hotel management personnel play an important role. Students in the actual teaching through the joint international hotel, students will be able to better familiar with the hotel work environment, understand the hotel market demand, a preliminary understanding of the hotel management environment, so that we can more in-depth clear their own development goals, and struggle. For the school-enterprise cooperation model, in essence, is the student's pre-job vocational skills training process, and the hotel can also be based on their own development needs to give priority to the overall selection of good quality students.

\section{Conclusion}

In general, the status of our country in the international is more and more important, with other countries more and more close ties, which the industry's talent have put forward higher requirements on the development of tourism Said, effectively led the hotel management gradually turned to the international economic market. Therefore, for the hotel industry, in order to achieve their own sustainable development, improve service quality, we must strengthen the training of international talent, which the hotel management-related teaching model put forward new requirements. In the process of cultivating the international management of the hotel, we need to focus on the formation of the high-quality international teaching team, which is the basic guarantee for cultivating the international talent, in the process of selecting the teaching content and designing the curriculum system. Finally, we need to strengthen the application of school-enterprise cooperation model, in the course of practice to gradually improve the overall quality of hotel management personnel and ability.

\section{References}

[1] Yu Shuang, Cheng Gong. Research on international talent cultivation mode of hotel management specialty in higher vocational colleges based on "order - based training" [J]. Talent, 2017, (13): 186-187.

[2] Cao Yanfen. High - level hotel management professional international talent training practice teaching reform and innovation [J].Journal of Taiyuan Urban Vocational College, 2015, (12): 100-101 (in Chinese with English abstract).

[3] Le Ying. Hotel management professional "immersion" bilingual teaching mode and international talent training model analysis[J / OL]. Contemporary education practice and teaching research, 2015, (12): 145 +138 (2015-12 -16).

[4] Liu Danqing, Li Yunfei, Wang Wenjun .In the scenic classroom to cultivate international tourism and hotel management personnel - Tianjin University of Commerce in Sino-US cooperation in overseas school teaching practice as an example [J]. Education and Teaching Forum, 2015 (29): 90-91.

[5] Zang Qilin, Zhou Ling, Chen Weina, Chen Lina, Shi Qing, Sun Jiaxi, Ren Wenying.Study and practice of international management of talent in hotel management [J]. China Vocational and Technical Education, 2015, (16): 96-100.

[6] Fang Min. Higher tourism vocational education international hotel management personnel training model empirical study - Zhejiang Vocational College of Tourism as an example [J]. Journal of Jilin Engineering and Technology Teachers College, 2015, 31 (03): 82-84.

[7] Wang Xiaojuan. Based on the "bilingual teaching" international talent training mode of exploration and practice - to the higher vocational colleges hotel management as an example [J]. Higher vocational education (Tianjin Vocational University), 2014, 23 (03 ): 49-52 + 95. 
[8] Chen Lina. Based on the international perspective of the tourism management professional talent training model case[J]. Oriental corporate culture, 2012, (24): 85.

[9] Journal editorial department. Shanghai Education Highland Project: "international hotel management professional talent training model practice and exploration" passed the acceptance [J].. Journal of Shanghai Business College, 2012,13 (01): 2. 